\title{
El Teatro de José Antonio Ramos
}

MPELIDo por un apremiante deseo de dialogar con su pueblo, buscó

Ramos las tablas para volcar en ellas sus preocupaciones de ciudadano. Entre los dramaturgos cubanos de la era republicana, Sánchez Galárraga le aventaja en fecundidad y frescura, Sánchez Varona en el diestro manejo de los elementos teatrales, Baralt en plasticidad y equilibrio, Salinas y Montes López en animadas pinturas de ambiente, pero es Ramos el único que con afanosa persistencia plantea y busca solución a los problemas de su patria y su generación. Por eso ninguno le iguala en reciedumbre ideológica.

La obra dramática de Ramos coincide cronológicamente con lo que lleva Cuba de república, y es, en cierto modo, reflejo vivo de sus vicisitudes. Casi un mozalbete aún, vela sus armas de caballero andante de la escena con una pieza cuyo título es ya promesa y presagio de su labor total: Almas rebeldes, drama en cuatro actos terminado antes de cumplir los veintiún años, y publicado en Barcelona en 1906 junto con otro drama en tres actos: Una bala perdida. En rápida sucesión siguen $N a n d a$, comedia dramática en tres actos (La Habana, 1907), y La hidra, drama también en tres actos (La Habana, 1908). Son éstas sus obras de juventud, petulantes y jactanciosas a veces, viriles y apasionadas siempre. Hoy sólo tienen el mérito de haber servido de aprendizaje a un escritor de fuerte fibra y personalidad vibrante. Además, Una bala perdida hubo de servir luego de base para su Calibán Rex y La hidra, con sustanciales cambios en trama, personajes y orientación, fué refundida en su admirable Tembladera.

A mediados de 1907 hace su primer salida a Europa. Vive en París, escribe en Madrid y vuelve a Cuba en 1909. Poco después 
de su regreso, funda, con Max Henríquez Ureña y Bernardo G. Barros, la Sociedad de Fomento del Teatro. Fué lucha aquélla contra impasibles molinos de viento. Las aspas de la indiferencia y del fracaso económico detuvieron momentáneamente los audaces arrestos de Ramos, mas no doblegaron su enhiesto penacho de ilusiones. Al contrario, para mellar el diente emponzoñado de quienes le negaban sentido teatral, escribe el sainete $A$ La Habana me voy... Regino López lo lleva a la escena del Payret, y el público, ávido de temas ligeros y gracia picaresca, le concede risueña acogida. Pero Ramos vuelve la espalda al señuelo de la taquilla, y con redoblado entusiasmo sigue bregando por un teatro de ideas. De esa empecinada dedicación surgen Liberta, novela escénica en cuatro jornadas, y Cuando el amor muere, primer acto de comedia, ambas publicadas en un solo volumen en 1911.

En Liberta se aventura Ramos en la selva de milenarias convenciones que aprisionan los impulsos de la mujer ante el poderoso estímulo de la carne, $y$, lanza en ristre, intenta liberarla de los prejuicios que conceden al hombre privilegios que a ella se le niegan. No había aprendido Ramos aún que la lógica falla donde los hábitos colectivos imperan. $\mathrm{Y}$ como la moralidad es selección y estratificación de hábitos colectivos tenidos por útiles al mantenimiento de una sociedad, esa sociedad reacciona negativamente ante el innovador que amenaza desquiciar los muros de barro en que aquélla confía su defiensa y conservación. Abrirles a esos muros aspilleras de luz con la pica de la sátira, como hace George Bernard Shaw, sí; pero derruirlos por completo, aunque sea a golpes de razón, no. Por eso Liberta ni halló ni pudo hallar público adepto en una nación tan conservadora y tradicional como la española. Todo cuanto logró Ramos fué que Benavente, el de los levísimos alfilerazos de ironía, le dijera en el prólogo que para Liberta escribió:

“...Si quiere usted ser autor aplaudido en público, no busque usted comedias en la vida, repase los archivos teatrales y sea usted uno de tantos.

"Si quiere usted ser... usted mismo ;Ah! ... Entonces contemporice usted en algo, porque en Arte hay que ser oportunista, como en política, como en todo... No es lo mismo engañar que hacer traición." 
Mejor fortuna que Liberta tuvo Cuando el amor muere... Es esta pieza un fino y poético primer acto de comedia en que se deja al público la tarea de suplir el desenlace. En ese primer acto, que es lógicamente de exposición, bucea Ramos en las profundidades del alma humana para sacar a flote la perla herida del amor que acaba. Es más, aquellos personajes, sin dejar de ser humanos, dan en conjunto la impresión de que son partes articuladas de un todo, que quienes realmente dialogan son las distintas etapas evolutivas de una sola pasión, desde don Distante Amor Incipiente (Fernando), hasta don Hastiado Amor Ahito (Roberto). Lo sugerente y nada convencional de la trama, y la constante elevación y cuidado del estilo, completan los méritos de esta obra. Traducida luego al inglés por Isaac Goldberg, fué publicada entre las veinticinco piezas internacionales en un acto, de que se compone la selección hecha por Frank Shay. Con ella la reputación de Ramos, que había salvado ya las fronteras de su patria, cruzó también las del idioma.

A fines de 1913 estrena simultáneamente en Barcelona y en La Habana su drama Satanás. Esta obra, inspirada en experiencias personales mientras visitaba parientes lejanos en España, se desarrolla en uno de esos lugarejos peninsulares, obscuros y obscurantistas, donde los habitantes vegetan en una torva atmósfera de fanatismo y superstición. A ese ambiente, que es el mismo de la Doña Perfecta de Galdós, regresa Esteban, artista librepensador y cosmopolita, en compañía de su protegida, Lisette. La presencia de Esteban y la joven produce la chispa que al rasgar la penumbra en que viven Pablo y Nicolás, hermano y sobrino, respectivamente, de Esteban, también prende fuego a sus acumuladas inhibiciones e inflama los acontecimientos en explosión de tragedia. Caracteriza esta obra la abundancia de situaciones dramáticas, y esa constante pugna de Ramos contra la cobardía que se hace pasar por virtud y la falsedad por decencia. De otra parte, falta tersura al diálogo y lucidez a la exposición. De ahí que no resalten con suficiente claridad las ideas de Esteban, ni surja por completo el drama latente. El polemista $y$ el reformador dejan rezagado al dramaturgo.

En el prólogo de Satanás declara nuestro autor el propósito que le animará en sus futuras creaciones al afirmar:

"Soy cubano, y todas mis aspiraciones, aun las inconfesables a fuer de fantásticas, van a mi patria. Que de allí saldrán algún día si tienen por qué salir." 
Ese propósito cristalizó inmediatamente en Calibán Rex, drama político cubano estrenado en La Habana en mayo de 1914 por la compañía de Miguel Muñoz. Esta obra, que trae a la memoria el tono y el tema de Un enemigo del pueblo, de Ibsen, es sajante análisis de una incipiente y enfermiza democracia. Algunas de las ideas que dos años después aparecerían en forma de ensayo en su Manual del perfecto fulanista, le agitan ya y le dictan las escenas angustiosas de este drama. Admirable es la altura de miras del protagonista, y aleccionador su fracaso. Sería Calibán Rex hito importante en la dramaturgia cubana si los detalles de la ejecución correspondieran al contenido ideológico. Desafortunadamente, hay numerosos personajes débiles, la trama es demasiado episódica y los largos parlamentos y difusas prédicas le restan fluidez y dramaticidad.

Al año siguiente publica en Cuba Contemporánea la pieza en un acto El traidor, que luego ha sido también traducida al inglés por el profesor W. K. Jones. En ella, a un diálogo rápido e intensamente emocional, aúna Ramos elementos de impresionante teatralismo - lobreguez nocturna, tormenta, descargas eléctricas- para crear el ambiente patético y fantasmal necesario al argumento: un episodio trágico de la independencia, inspirado en los siguientes versos de Martí:

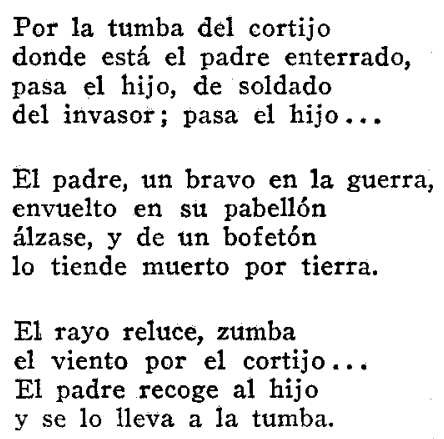

Debe añadirse que el haber descubierto el sentido dramático de esos versos y haber plasmado su asunto en forma teatral no es el único punto de contacto entre Ramos y Martí. Al contrario, sin presumir de ello, ha sido Ramos constante admirador del Mártir de Dos Ríos, y su pensamiento está vitalmente impregnado del ideario martiano. 
En ese mismo año publicó otra obra también de ambiente cubano: El hombre fuerte, drama en tres actos (Madrid, 1915). El título es irónicó: no hay tal hombre fuerte en este drama. Vicente Inclán, un extrovertido audaz y materialista, cuyas energías parecen transformarse en pesos y sus pesos en mandatos, es un hombre incompleto porque desconoce el mundo del espíritu. Su antagonista, carácter reflexivo y filosófico, es igualmente incompleto porque carece de sentido de la realidad. Este, Ramiro, cuya ceguera física es simbólica de sus limitaciones mentales, resulta transitoriamente derrotado por Inclán al disputarse ambos el amor de Elena. Pero Inclán, aunque logra hacerla su esposa, con su burda incomprensión, la arroja luego en brazos de su contrincante. $\mathrm{Y}$ es la incapacidad de acción de ese hombre aparentemente fuerte lo que conduce a la tragedia final, en que cae fulminado al perder la esposa y saberse engañado. Ramos ha buscado aquí ocasión de dialogar consigo mismo. En su entusiasmo creador, desdobla al hombre equilibrado en dos personalidađes opuestas: el Calibán sin espíritu y el Ariel sin materia. De la unión armoniosa de esos elementos se compone el hombre verdaderamente fuerte. Hay en esta obra atropellada brillantez y tumultuoso hervor de ideas. También olvido desdeñoso de la forma, que en Ramos siempre está clamando poda y ordenación.

Dos años después termina Tembladera, que a más de ser uno de los más acabados dramas con que cuentan las letras cubanas, es el que mejor ejemplifica el ardoroso empeño de Ramos de servir a la patria. En él logra el autor el triple propósito de plantear un problema capital cubano, ofrecerle solución y hacer buen teatro. Por primera vez se unen en un escritor instilar las características del sociólogo, el pensador y el dramaturgo. No es extraño que, al presentar esta obra al concurso de literatura de 1916-1917 de la Academia Nacional de Artes y Letras, obtuviera el primer premio.

El problema abordado en Tembladera es la explotación de la tierra. Cuba, eminentemente agrícola, veía pasar a manos extrañas las fincas azucareras, y el dinero de las ventas, en lugar de invertirse en fomentar nuevas riquezas, lo despilfarraban señoritos inservibles, parásitos destructores de la sana economía nacional. Ramos, buscando los verdaderos orígenes del mal, pone bajo su lupa de sagaz observador una familia representativa de la clase directora. Halla en su seno las causas del disolvente fenómeno y las expone a la luz 
de las candilejas de manera que su tesis aparezca sólo como resultado indirecto de una trama emocionante y bien motivada.

Esa trama es, en sintesis, una serie de voluntades que se cruzan $y$ entrecruzan en torno de un punto central: la venta de Tembladera, el ingenio de la familia Gonsálvez de la Rosa. Los hechos se precipitan con la fechoria cometida por Gustavo al comenzar el drama, y desde ese momento se desarrolla la acción como un huracán que llega, todo lo envuelve, y luego se aleja dejando tras sí devastación y duelo.

Arrastrados por el vendaval de esa acción, como aquellas almas torturadas del infierno dantesco donde pagan Paolo y Francesca su pecado de amor, van pasando en rápida sucesión las fallas, hechas carne y dolor, de la sociedad cubana. Pasa don Fernando Gonsálvez de la Rosa, el anciano español que ha hecho familia y fortuna en Cuba, pero no ha sabido trasmitir a sus hijos su laboriosidad y honradez; pasa Maela, su mujer, débil de carácter y de intelecto, interesada en el bien físico de los suyos, pero incapaz de sospechar planos más elevados de actividades humanas; pasa Mario, el hijo mayor del matrimonio, educado en Madrid y españolizado hasta ser un total extranjero en su patria; pasa Gustavo, deplorable producto del relajamiento físico y moral que desafortunadamente crea a veces la molicie criolla; pasa Teófilo, jovenzuelo egoísta, dado a ese choteo acerbadamente iconoclasta para el cual nada hay noble ni puro. En contraste con esos elementos de disolución, pasa, torturado también, Joaquín Artigas, cuya laboriosidad y sana visión parecen destinadas a hundirse en aquella vorágine de desenfrenados egoísmos. Junto a él, serena y digna, pasa Isolina, expiando, como Francesca el pecado de su juventud. Y pasan Isabel, la candorosa hija de Joaquín; Luciano, el español encariñado con su nueva patria; María, la criada, y el funesto Carpetbagger.

Ahora bien, no todo es infernal pesadilla. En Joaquín e Isolina encarna la esperanza para el porvenir de Cuba. Hacen falta en la zarandeada isla antillana más hombres de fe, más mujeres de corazón, que, abandonando la indolencia atrofiadora de sus mansiones capitalinas, sepan acercarse con amor a la soleada tierra nativa, a crear el tipo de "gentleman farmer" criollo que con su espíritu emprendedor y su recia voluntad haga innecesaria la presencia de los Carpetbaggers. Cubanos de ese temple son los que deben dirigir las empresas agrícolas y salvar a su patria del suicidio económico. Con 
ellos renacería, adaptado a las condiciones del siglo $\mathrm{xx}$, el terrateniente que durante el siglo XIX perdió en la manigua la libertad económica luchando por ganar la libertad política.

Tembladera es la obra maestra de Ramos. Escrita con afortunada lucidez y energía, y cohesivamente desarrollada, pese a la multiplicidad de sus motivos dramáticos, esta pieza quedará, después de discretos retoques que la aligeren y perfilen, como lo mejor y más noble que ha dado una pluma cubana para ese teatro nacional que ineluctablemente nos ha de llegar.

Después de la publicación de Tembladera, volvió a salir Ramos para el extranjero. Reside por largos años en Norteamérica y luego, en 1932, pasa a México. El problema religioso palpitante a su llegada a la república azteca, despertó su espíritu generoso y combativo. Su sensibilidad de dramaturgo vibró fuertemente estimulada por el contraste entre el uso racional que de sus energías hace el hombre progresista, para labrar su bienestar, y el fatalismo cansino de los que se sientan a esperar que Dios provea para ellos como lo hace para los bíblicos lirios de los campos. "In the lap of the gods" se dijo, pensando en inglés. $\mathrm{Y}$ de allí nació En las manos de Dios.

E1 pensamiento central de esta obra se expresa todo en el prólogo dramático que precede a la acción real, prólogo que es verdadero psicoanálisis puesto en escena. En él aparecen los miembros de una familia próximos a perecer. La hija se cree capaz de salvarse por medios irracionales y exclama: " $i$ En tus manos estamos, Señor! ¿No nos dejes morir en pecado mortal! ¿ Haz que sintamos el milagro de tu sabiduría divina! Yo estoy pronta, Señor ... i Estoy salva! ¡Salva!" Su hermano, por el contrario, consciente de que el microbio no cesará su destructora labor por súplicas supersticiosas, pide al médico que llega, le ponga la única inyección que queda de la substancia salvadora. E1 joven desea vivir "para la Ciencia, para el Saber, para la Verdad". Pero el deslumbrado galeno acude primero a ella, no a él...

A este prólogo, moderno por el empleo de un escenario a obscuras donde mediante efectos lumínicos se produce un vago ambiente espectral, sigue una acción realista, impregnada del instrumentalismo de Dewey, en la cual otra vez trata Ramos de envolver en el manto de la trama el desnudo cuerpo de una tesis. La escena cambia del mundo tenebroso del prólogo a un laboratorio lleno de luz donde trabajan - nótese el simbolismo que encierran los nombres- el doc- 
tor Prometeo y María de la Fuente, su abnegada ayudante. E1 tercero en estas labores científicas, Elpidio, hijo mayor y esperanza del doctor, les ha abandonado atraído por la belleza superficial de María del. Pozo. Estas dos Marías son polos opuestos: laboriosa, excelente compañera de trabajo la primera; holgazana, estúpidamente incomprensiva la segunda. El viejo doctor comprende la necesidad de que su hijo vuelva a sus relaciones con la Fuente. $Y$ tomando una decisión de hombre que se sabe por encima del juicio de la sociedad, cambia el contenido de la ampolleta que ha de inyectársele a María del Pozo, y es causante de su muerte. En el segundo acto, bastante farragoso, Elpidio regresa a la vida de investigador. Esta vez, la firme voluntad de Prometeo había salvado a su hijo para la ciencia y la humanidad.

Innecesario es decir que un drama de tan atrevidas ideas no ha de ganar el aplauso de damas santurronas, muchachas vacías y petimetres sin masculinidad a quienes Ramos violentamente critica y caricaturiza en doña Caridad, María del Pozo, Cuca, Loló y Bebito. Es, sin embargo, obra de estimulante lectura para quienes pueden proyectar su pensamiento al futuro y concebir tin mundo mejor, nacido del esfuerzo y la dignidad humanos.

A este drama siguen cronológicamente dos piezas menores: $L a$ leyenda de las estrellas y La recurva. La primera, estrenada en el Círculo de Bellas Artes de La Habana en diciembre de 1935, es un paso de comedia de sabor pirandeliano. Con penetración poética $\mathrm{y}$ fino sentido social muestra Ramos que la verdad no es lo que el hombre sincero dice, sino lo que sus interlocutores esperan y desean oír de sus labios. Tanto por la sencillez del argumento, con situaciones que recuerdan algunas de The Hairy Ape de O'Neill, como por la agilidad de los conceptos y grácil elocución, es ésta tal vez la más delicada y amena de todas sus obras: La recurva, en marcađo contraste, es un trozo escueto de conversación en una casa de campo cubana, mientras fuera ruge el huracán. Realista y sin trama aparente, en ella se plantea el problema entre la vieja y la nueva generación durante los años caóticos que siguen a la caída de Machado. Es, en cierto modo, una variación del tema de Tembladera, modernizado en sus fuertes disonancias y concentrado en las breves dimensiones de un acto. Escrita en 1939, se imprimió en 1941 junto con El traidor y La leyenda de las estrellas. 
En 1944 publica Ramos la última de sus obras teatrales: $F U$-3001. La infunde y motiva una consideración de las contradictorias decencias que en la pieza conversan. Otea el horizonte político y moral de aquel momento, y lo pinta como creyó verlo. El resultado es un cuadro en monótonos blanco y negro. Los personajes son simples percheros a los cuales se cuelga una alabanza o una crítica, y no pocos de ellos estarían de más en una pieza escrita con estricta economía teatral. Ramos recarga, polemiza, sermonea y olvida que el buen teatro es evocador, que el público gusta de que cuenten con su imaginación antes de ofrecer el aplauso tácito de la emoción sentida. El, por el contrario, desdeña la colaboración de ese mismo público por el que luchaba a brazo partido organizándole bibliotecas y buscándole libros. Es el caso patético de un hombre que habló con rudeza a quienes amó con ternura. Por todo eso, más que la obra, me interesa un párrafo del prólogo en que Ramos condensa, presintiendo ya su próximo ocaso, el credo artístico que iluminó su labor de autor dramático. Dice:

"A mí me importa el teatro como arte social en acción, como creación artística, como expresión en diálogo - forma platónica universal e insuperable- de todo lo que siente y piensa un pueblo, a través de sus más amorosos y profundos exégetas."

Amoroso y profundo exégeta de su pueblo. He ahí, en resumen, y de cuerpo entero, a José Antonio Ramos el dramaturgo.

José JuAN Arrom, Yale University. 
